\title{
BEHAVIOUR OF TIMBER PORTAL FRAME DEPENDING ON ROTATIONAL STIFFNESS OF KNEE JOINT
}

\author{
Janis Fabriciuss, Lilita Ozola \\ Latvia University of Life Sciences and Technologies, Latvia \\ janis.fabriciuss@inbox.lv
}

\begin{abstract}
In this article, the topic under discussion is the development of deformations in semi-rigid knee joints made of dowel type fasteners and consequences expected regarding overall deformations of timber portal frame structure. The use of semi-rigid connection resolves the problem of transportation, but development of small rotation in connection reduces the stiffness of the connection that becomes significant during service life. It is assumed that the rotational stiffness modulus $K_{\varphi}\left(\mathrm{kNm} \cdot \mathrm{rad}^{-1}\right)$ is the relevant characteristic of semi-rigid connection. Timber portal frame structure (span $30 \mathrm{~m}$ ) designed with dowel type fasteners located around two circles has been subjected to different loading trials by using Dlubal software (RFEM). Results of a numerical study of portal frame model demonstrate the importance of characteristics of semi-rigid knee joints for design. It is found that developing deformations in the semi-rigid knee connection produce up to $90 \%$ bigger vertical displacement at an apex point and $96 \%$ bigger horizontal displacement comparing with the rigid knee joint model.
\end{abstract}

Key words: semi-rigid timber connection, numerical study.

\section{Introduction}

During recent decades timber portal frame structures have become at the forefront more often when one chooses structural form for the design industrial building. Portal frame structure requires a shorter assembly time in comparison with a columntruss type frame. Portal frame forms a geometrically stable structure if knee joints are rigid, i.e., fasteners used are able to avoid the rotational movement between column and rafter elements. Knee joints of timber portal frames may be executed as glued finger joints or semi-rigid connections made by mechanical fasteners. From a static point of view, glued knee joints are safer representing clear conformity with a traditional model accepted for structural design of three hinged frames. Yet the limitations for sizes of prefabricated units due to transportation conditions take down an overall area of the use of these portal frames. The use of a semi-rigid connection enables us to avoid the problems regarding limitations of transportation, as in this case knee joint between column and rafter elements may be assembled at the building site, and transportable units are separate column and rafter elements. At the same time design assumptions for portal frames made with mechanical fasteners in the knee joints are more complex; moreover, they contain some unexplored details. In the knee joint made with mechanical fasteners the force transferring mechanism from the rafter to column element is significantly distinctive from the glued one. The single rafter units of a portal frame are usually enclosed by two glulam column elements. Bending moment created by external load is transferred step-bystep - wood-fasteners-wood. The procedure is followed by larger or smaller change of angle between the rafter and column, i.e., increase of rotational movement of connected elements. The rotation between timber elements in connection is increased due to deformations of mechanical fasteners, as well as by fastener's embedment action into wood. The result in this type of knee joint falls into class of semi-rigid connections. Rotational displacement in knee connection may affect the global behaviour of portal frame significantly under design loads (Figure 1, a).

The rigidity of connection may be characterized by the rotational stiffness $K_{\varphi}\left(\mathrm{kNm} \cdot \mathrm{rad}^{-1}\right)$ expressed by the value of bending moment value per one radian of angle change between connected elements. In Eurocode 5 (European committee for standardization, 2008) slip modulus $K_{\text {ser }}$ for connections is defined representing the axial displacements between connected elements loaded in tension or compression. It is doubtful that deformation of knee joint may be expressed correctly using linear slip modulus $K_{\text {ser }}$ (Fokkens, 2017). It is found from the results of previous experiments (Ozola \& Fabriciuss, 2019) that $K_{0}$ value is in the range from $35 \cdot \mathrm{Md}-75 \cdot \mathrm{M}_{\mathrm{d}} \mathrm{kNm} \cdot \mathrm{rad}^{-1}\left(\mathrm{M}_{\mathrm{d}}-\right.$ moment capacity of connection).

Firstly, an examination of the force and stress distribution in the joint area, including the calculation method, was presented by Racher (Timber Engineering (1995). During the last decades investigations on behaviour of timber portal frames with semi-rigid knee joints were carried out by many researchers. Analysing behavior of semi-rigid connection in the two storey orthogonal frame, Leichti concluded that the moments at the connection may be expressed as the function of stiffness properties (Leichti et al., 2000). Bouchair et al. developed a two-dimensional finite element model of dowelled joint confirming the fact that the geometrical centre of the dowels can be used as a mechanical rotational centre of the joint (Bouchair, Racher, \& Bocquet, 2007), and underlying need for criterion also regarding stresses interaction between the shear and the tension perpendicular to the grain. Scheibmair 


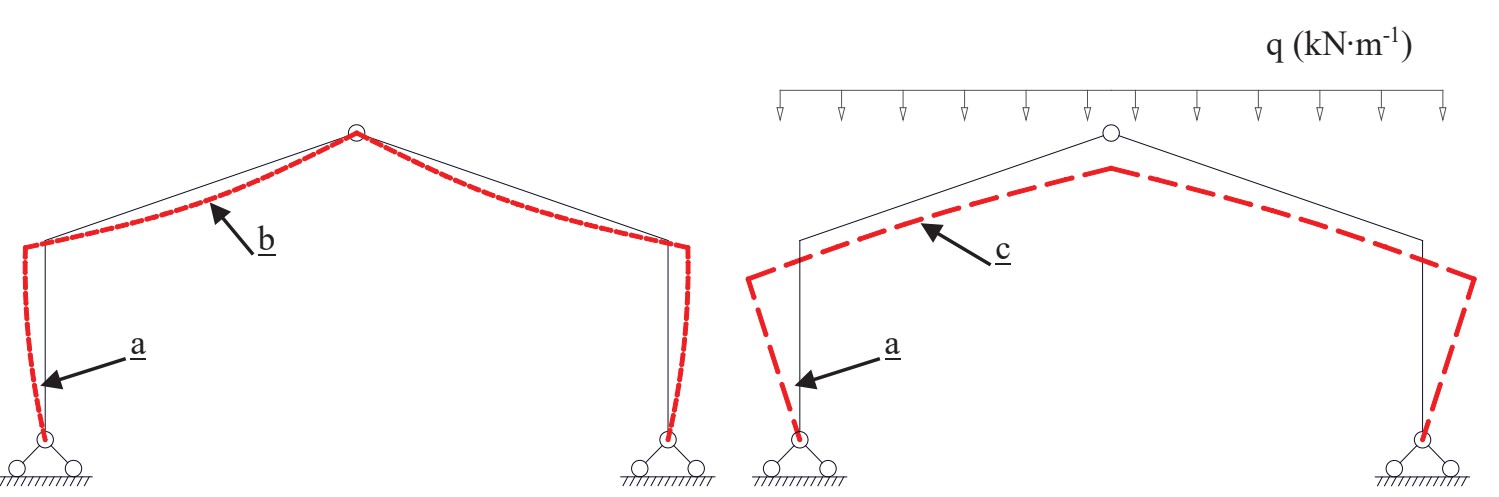

Figure 1. Portal frame model; $a$ - ideal design shape of portal frame; $b$ - assumed initial deviation in the geometry for a frame; $\mathrm{c}$ - deformed shape under load.

and Quenneville proposed moment connection with fully threaded screws inserted at 60 degrees to the load (Scheibmair \& Quenneville, 2010). Morris and Quenneville executed a test programme of portal frame knee joint realising the moment redistribution on two pin portal frame model (Morris \& Quenneville, 2010). Gehloff et al. proposed the use of reinforcement to prevent splitting of timber through edge lines (Gehloff, Closen, \& Lam, 2010). Completed study of semi-rigid knee joints of timber portal frames was presented by Porteous and Kermani resulting with methodology for determination of connection's design capacity (Porteous \& Kermani, 2013). Nevertheless, experimental results (Ozola \& Fabriciuss, 2019) show that a huge rotation can be found at the connection under external loads and cannot be ignored when one is designing a semi-rigid connection. In addition, it is noteworthy, that most of the experimental investigations under short-term static loading were carried out.

In the current study, the classic model for structural analysis of portal frame (Figure 1) is supplemented with additional effects due to anticipated rotational displacements in semi-rigid knee joints (Schweigler, Bader, \& Hochreiner, 2018), as well as taking into account the initial imperfections of the form defined by Eurocode 5 (European committee for standardization, 2008).

Duration of load effect is a very important issue for timber structures with dowel-type fasteners. The prognosis of effect from a long-term loading is unclear, because of many different factors, such as moisture content, stress level (as a ratio to capacity), temperature, a variation of wood density and many others, affecting the structural phenomena.

The aim of the study is to assess the effects of deformations of semi-rigid connection to internal forces and displacements of structure.

\section{Materials and Methods}

In this study, the model of timber portal frame with semi-rigid knee joint has been tested using Dlubal software (RFEM). Research was carried out in the Latvia University of Life Science and Technologies, Faculty of Environment and Civil Engineering during March, 2019. A portal frame structure was designed by built-up columns made of glue laminated tapered timber elements and of single rafter elements. The initial design of a portal frame under a design load $12.7 \mathrm{kN} \cdot \mathrm{m}^{-1}$ was carried out assuming completely rigid knee joints. The span of a portal frame is $30 \mathrm{~m}$, apex height $-14.5 \mathrm{~m}$, the slope of rafter elements $-19^{\circ}$. Vertical design load $\mathrm{q}_{\mathrm{d}}=12.7 \mathrm{kN} \cdot \mathrm{m}^{-1}$ attached to rafters represents a combination of permanent selfweight and medium-term snow load. Wind pressure is not taken into account in this study because its influence on longterm behaviour of knee joints may be assessed as insignificant. Cross section sizes of column at the knee joint are $2 \times 200 \times 1600 \mathrm{~mm}$, but at the column base $2 \times 200 \times 600 \mathrm{~mm}$. Rafter cross section sizes are $300 \times 1600 \mathrm{~mm}$ at the knee joint and $300 \times 800 \mathrm{~mm}$ at apex point (Figure 2). Strength class of glue laminated timber is GL24h.

Knee joint was designed with dowel type fasteners located around two circles. The radius of an external circle is $r_{\max }=640 \mathrm{~mm}$, and 26 fasteners are arranged around the circle taking into account the limitations for distances between fasteners according to Eurocode 5 (European committee for standardization, 2008); see Figure 3. Radius of an internal circle is $r_{i}=400 \mathrm{~mm}$ and 16 fasteners are located around that. Bolts M24 (grade 8.8) were used as fasteners.

Assumptions for engineering modelling of a semirigid connection have been discussed in detail by researchers (Hochreiner et al., 2016), (Ormarsson, Dahlblom, \& Nygaard, 2010). Before numerical analysis of a frame in deformed state, the design capacity was calculated for moment-resisting knee joint assuming fully rigid knee joint. Theoretical moment capacity $\left(\mathrm{M}_{\mathrm{d}}\right)$ was found according to the methodology developed for dowelled frame corner design (Timber Engineering, 1995). In Figure 3 the exact solution of a knee joint of portal frame chosen 

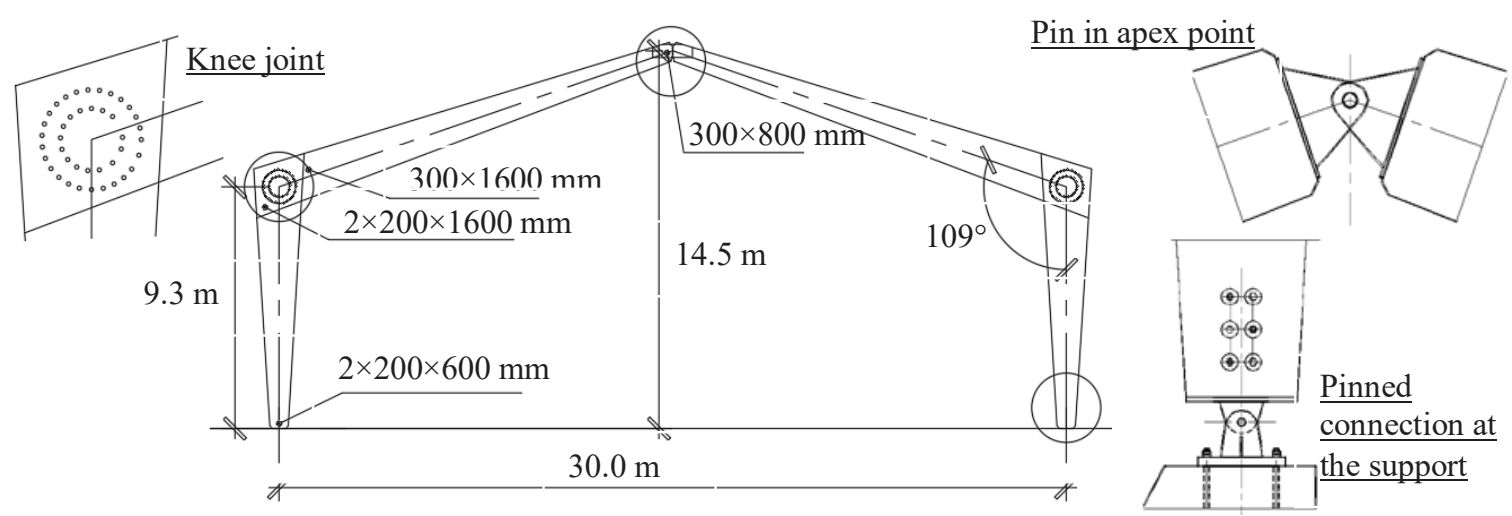

Figure 2. Timber portal frame structure.

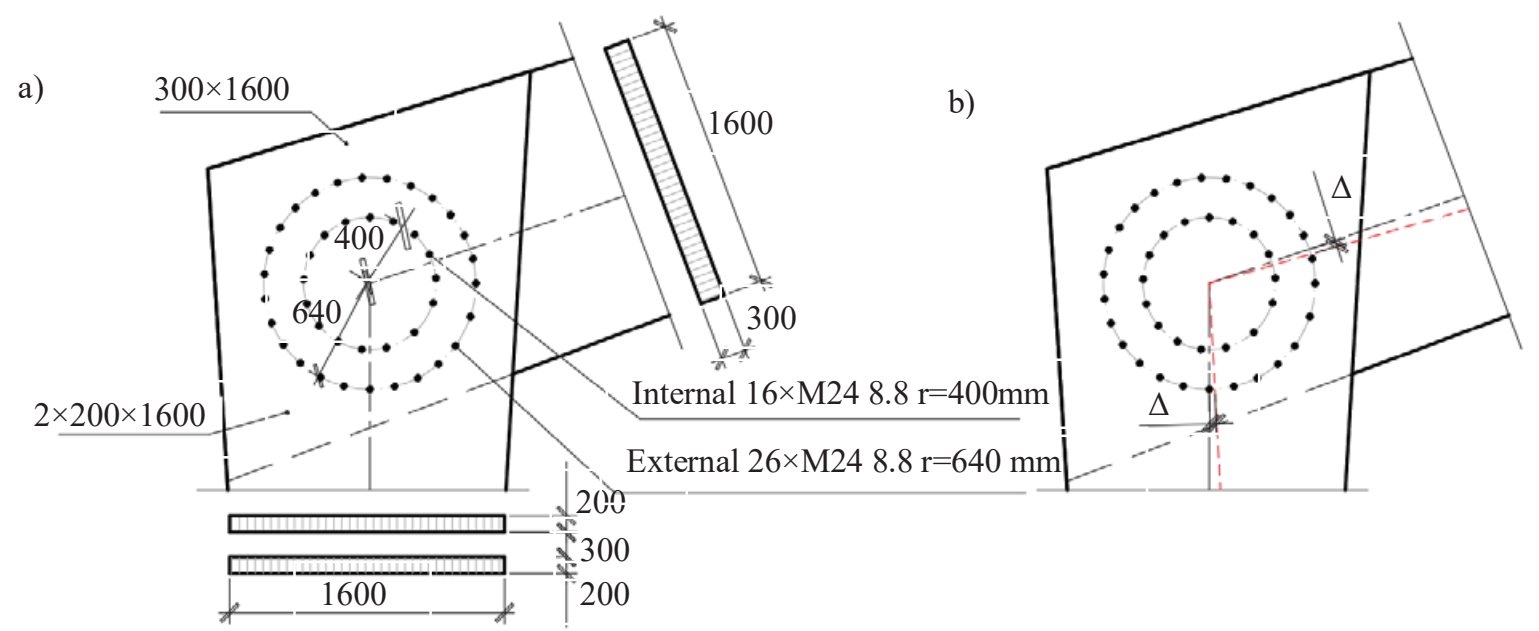

Figure 3. Solution of semi-rigid knee joint: a - connection design; b - rotational movement in connection.

for analysis is shown. In keeping with diameters of circles around which dowels are placed, design moment capacity of knee joint is $936 \mathrm{kN} \cdot \mathrm{m}$. Using existing static equilibrium equations for three hinged frames corresponding horizontal and vertical reactions were found, which led to relevant symmetrically distributed vertical design load value $\mathrm{q}_{\mathrm{d}}=12.7 \mathrm{kN} \cdot \mathrm{m}^{-1}$ to be attached to the frame rafter.

Rotational stiffness values assigned for analysis based on a logical assumption on displacements expected in the knee joint due to the following action effects were found:

- free displacement of bolt in hole (due to allowance $1 \mathrm{~mm}$ ),

- deformation of bolts in bending,

- embedment of bolt into wood (up to $1 \mathrm{~mm}$ proposed).

The bending moment values per radian of an angle of rafter's and column's axis rotation correspondingly to expected displacement values $\Delta_{1}=1 \mathrm{~mm}, \Delta_{2}=1.5 \mathrm{~mm}$ and $\Delta_{3}=2 \mathrm{~mm}$ were assigned as rotational stiffness modulus $320 \cdot \mathrm{M}_{\mathrm{d}}, 213 \cdot \mathrm{M}_{\mathrm{d}}, 160 \cdot \mathrm{M}_{\mathrm{d}}$ (see Table 1 ). For the design of an original model knee joint rotational stiffness was assumed $\mathrm{K}_{\varphi}=\infty \mathrm{kNm} \cdot \mathrm{rad}^{-1}$.
First, the distributed vertical load $\mathrm{q}_{\mathrm{d}}=12.7 \mathrm{kN} \cdot \mathrm{m}^{-1}$ was attached to the portal frame structure. A knee joint stiffness was defined as infinity $\mathrm{K}_{\varphi}=\infty$. This model of the system was used as reference one for the next trials of the numerical test when internal forces and point displacements were calculated assuming a deformed shape of the design model.

Second, a model of an imperfect shape was introduced and similar steps of static analysis were carried out. Increased displacements and internal forces were found when an imperfect shape of the system was introduced in an input data. See values of internal forces and displacements in Table 1.

\section{Results and Discussion}

Results of numerical analysis show that displacement of an apex point changes significantly by changing the knee joint stiffness values (Figure 4). Similar results were gained in previous investigation (Malo \& Stamatopoulos, 2016). Assuming a rigid knee joint $\left(K_{\varphi}=\infty\right)$, a vertical displacement of an apex point may be prognosticated of $68.9 \mathrm{~mm}$. Introducing semi-rigidity constant as a knee joint parameter, the apex point displacements take values in the range from 


\section{Displacements of deformed shape portal frame nodes and internal forces}

Table 1

\begin{tabular}{|c|c|c|c|c|c|c|}
\hline $\begin{array}{l}\text { Rotational } \\
\text { stiffness } \\
\text { assumed } \\
\mathrm{kN} \cdot \mathrm{m} \cdot \mathrm{rad} 10^{-3}\end{array}$ & $\begin{array}{c}\text { Horizontal } \\
\text { displacement } \\
\text { of a knee point } \\
\Delta_{1} \mathrm{~mm}\end{array}$ & $\begin{array}{c}\text { Vertical } \\
\text { displacement } \\
\text { of a knee point } \\
\Delta_{2} \mathrm{~mm}\end{array}$ & $\begin{array}{c}\text { Vertical } \\
\text { displacement of } \\
\text { an apex point } \\
\Delta_{3} \mathrm{~mm}\end{array}$ & $\begin{array}{c}\text { Moment } \\
\text { capacity of } \\
\text { a knee joint } \\
\mathrm{kN} \cdot \mathrm{m}\end{array}$ & $\begin{array}{c}\text { Axial force } \\
\text { in column at } \\
\text { a knee joint } \\
\mathrm{kN} \cdot \mathrm{m}\end{array}$ & $\begin{array}{l}\text { Shear force in } \\
\text { rafter section at a } \\
\text { knee joint } \mathrm{kN} \cdot \mathrm{m}\end{array}$ \\
\hline \multicolumn{7}{|c|}{ Original three hinged model with rigid knee joints } \\
\hline$\infty$ & -0.3 & 23.1 & -68.9 & 936.64 & -192.71 & 149.38 \\
\hline \multicolumn{7}{|c|}{ Deformed shape model assuming semi-rigidity (rotation) effects in knee joints } \\
\hline$\infty$ & -0.3 & 23.1 & -68.9 & 945.5 & -192.78 & 150.22 \\
\hline $320 \cdot \mathrm{M}_{\mathrm{d}}$ & -0.3 & 33.6 & -99.3 & 949.5 & -192.78 & 150.59 \\
\hline $213 \cdot \mathrm{M}_{\mathrm{d}}$ & -0.3 & 38.8 & -114.5 & 951.6 & -192.78 & 150.78 \\
\hline $160 \cdot \mathrm{M}_{\mathrm{d}}$ & -0.3 & 44.1 & -129.6 & 953.6 & -192.79 & 150.97 \\
\hline \multicolumn{7}{|c|}{ Deformed shape model assuming semi-rigidity (rotation) effects in knee joints + imperfect shape } \\
\hline$\infty$ & -0.3 & 23.1 & -70.4 & 945.6 & -192.76 & 150.22 \\
\hline $320 \cdot \mathrm{M}_{\mathrm{d}}$ & -0.3 & 34.6 & -101.4 & 951.7 & -192.79 & 150.74 \\
\hline $213 \cdot M_{d}$ & -0.3 & 39.9 & -116.1 & 954.1 & -192.80 & 150.99 \\
\hline $160 \cdot \mathrm{M}_{\mathrm{d}}$ & -0.3 & 45.3 & -131.2 & 956.1 & -192.81 & 151.18 \\
\hline
\end{tabular}

$99.3 \mathrm{~mm}$ to $129.6 \mathrm{~mm}$ (Table 1 ). It is clear that stiffness of connection significantly affects deformations of the portal frame. Deformations in the semi-rigid knee joint promote an increase in portal frame deformations up to $88 \%$ referring to a traditional design model with a rigid connection (Table 2). When geometric imperfections of shape are introduced additionally, the displacement of the apex point increases by $2-3 \%$.

The moment capacity of the knee connection calculated for the original portal frame model is 936.64 $\mathrm{kN} \cdot \mathrm{m}$ (connection design bearing capacity). Taking into account expected deformations in the knee joint under the action of an external load, the bending in the knee joint increases up to $945.5 \mathrm{kN} \cdot \mathrm{m}$ comparing with the rigid connection design, and from 949.5 to 953.6 $\mathrm{kN} \cdot \mathrm{m}$ by a semi-rigid design. Introducing effects of the model imperfections, the bending moment increases in a range of 951.7 to $956.1 \mathrm{kN} \cdot \mathrm{m}$. An average bending moment increase is about 2\% (Figure 5) comparing with a rigid connection design (Table 2). The effects of geometric shape imperfections cause an additional moment increase of $0.1-0.3 \%$ (Figure 5 ). From the

Table 2

\section{Comparison of displacements and internal forces in system with semi-rigid knee joint referring to traditional model (\%)}

\begin{tabular}{|c|c|c|c|c|c|c|}
\hline $\begin{array}{l}\text { Rotational } \\
\text { stiffness } \\
\text { assumed } \\
\mathrm{kN} \cdot \mathrm{m} \cdot \mathrm{rad} 10^{-3}\end{array}$ & $\begin{array}{c}\text { Horizontal } \\
\text { displacement } \\
\text { of a knee point }\end{array}$ & $\begin{array}{c}\text { Vertical } \\
\text { displacement } \\
\text { of a knee point }\end{array}$ & $\begin{array}{c}\text { Vertical } \\
\text { displacement of } \\
\text { an apex point }\end{array}$ & $\begin{array}{c}\text { Moment } \\
\text { capacity of a } \\
\text { knee joint }\end{array}$ & $\begin{array}{l}\text { Axial force in } \\
\text { the column at a } \\
\text { knee joint }\end{array}$ & $\begin{array}{c}\text { Shear force } \\
\text { in a rafter } \\
\text { section at a } \\
\text { knee joint }\end{array}$ \\
\hline \multicolumn{7}{|c|}{ Deformed shape model assuming semi-rigidity (rotation) effects in knee joints } \\
\hline$\infty$ & 0 & 0 & 0 & 0.9 & 0 & 0.6 \\
\hline $320 \cdot \mathrm{M}_{\mathrm{d}}$ & 0 & 45.5 & 44.1 & 1.4 & 0 & 0.8 \\
\hline $213 \cdot \mathrm{M}_{\mathrm{d}}$ & 0 & 68.0 & 66.2 & 1.6 & 0 & 0.9 \\
\hline $160 \cdot \mathrm{M}_{\mathrm{d}}$ & 0 & 90.9 & 88.1 & 1.8 & 0 & 1.1 \\
\hline \multicolumn{7}{|c|}{ Deformed shape model assuming semi-rigidity (rotation) effects in knee joints + imperfect shape } \\
\hline$\infty$ & 0 & 0 & 2.2 & 1.0 & 0 & 0.6 \\
\hline $320 \cdot \mathrm{M}_{\mathrm{d}}$ & 0 & 49.8 & 47.2 & 1.6 & 0 & 0.9 \\
\hline $213 \cdot \mathrm{M}_{\mathrm{d}}$ & 0 & 72.7 & 68.5 & 1.9 & 0 & 1.1 \\
\hline $160 \cdot \mathrm{M}_{\mathrm{d}}$ & 0 & 96.1 & 90.4 & 2.1 & 0.1 & 1.2 \\
\hline
\end{tabular}




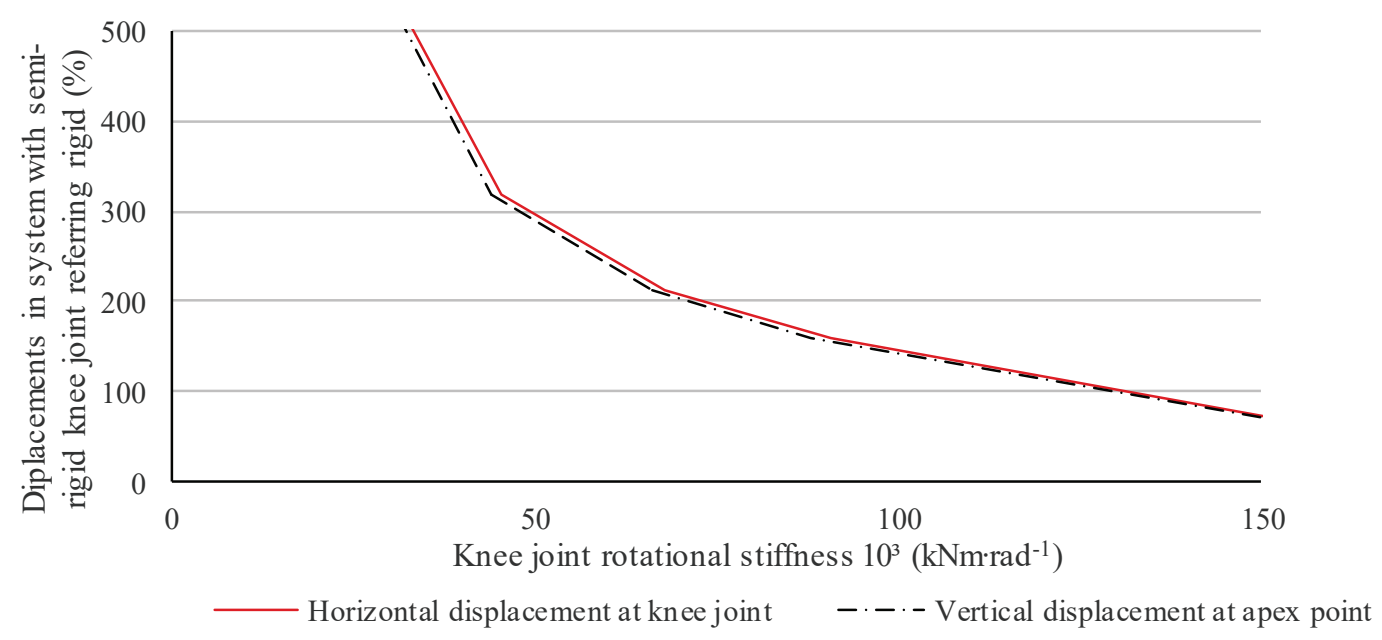

Figure 4. Apex point displacement depending on rotational stiffness of a knee joint.

results can be seen that a huge impact was from the external load that deformed the portal frame structure and increased influence if rotational stiffness in the connection were lower. Otherwise, the influence of imperfect shape was smaller (20 times smaller than from the external loading) and not directly related with knee joint connection stiffness.

Axial compression force value in the column at the section around knee joint is $192.71 \mathrm{kN}$ when the rigidity withstands. Introducing a possible rotational displacement of a semi-rigid knee joint and an effect from the imperfect shape, axial force value changes up to $192.81 \mathrm{kN}(0.1 \%)$.

Shear force at the rafter section around knee joint according to original design is $149.38 \mathrm{kN}$. Taking into account semi-rigidity effect, shear force values change from $0.8 \%$ to $1.1 \%$. Also, introducing the imperfect shape parameters, shear force changes in the range from $0.9 \%$ to $1.2 \%$.
In this study, the level of significance of influence of connection stiffness (characterized by so called spring constant) to overall deformation of a structure is found. Overall results show small differences among internal forces but significant ones regarding the movement of a knee joint and apex point. Vertical displacement of an apex point may reach up to portion of $1 / 200$ of the span of a portal frame. This is a warning that there is a possibility that some of serviceability limit states might take place. General limitation for apex point displacement may be assumed in the range of $\mathrm{L} / 400$ up to $\mathrm{L} / 300$ where $\mathrm{L}$ is a distance between support axis (span). Moreover, development of plastic deformations embedding bolts into wood, as well as creep of wood material will be additional effects actual during the service life and leading to an increase of overall deformations of a portal frame.

Note that the effect of friction between planes of timber elements was neglected in the current research.

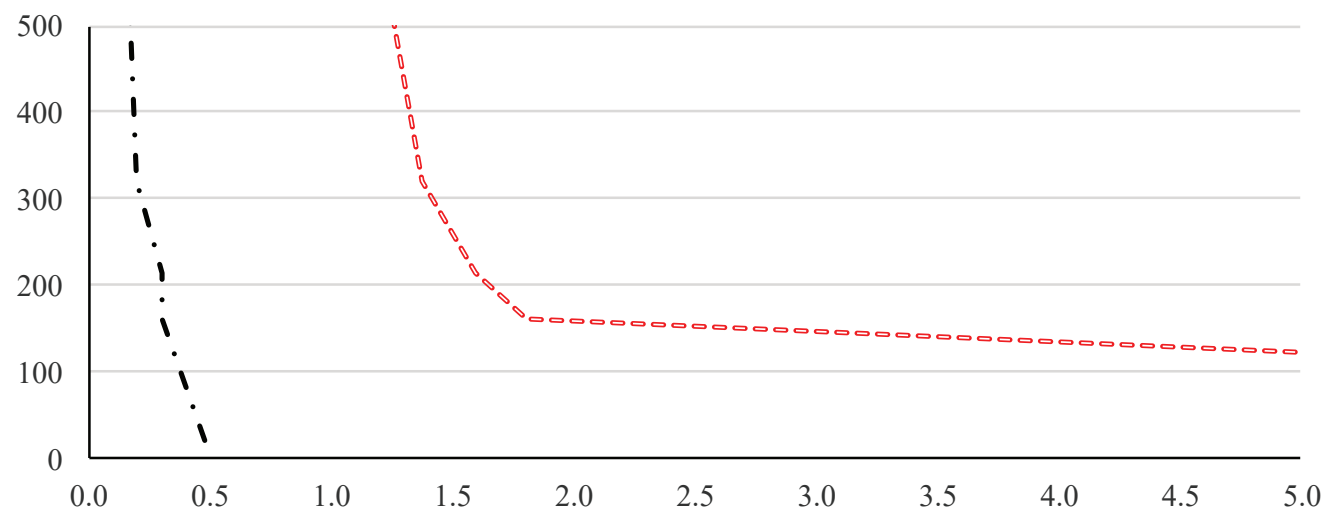

Ratio of bearing moment at knee joint if connection are defferent rotational stiffneses

$\infty \infty^{\circ}$ Influence from deformed shape under external load

- - Influence of imperfect shape

Figure 5. Influence of bearing moments according to timber portal frame knee joint stiffness. 
Normally friction reduces rotational displacement of elements connected at the knee joint. But friction effect can't be assessed as longterm phenomena due to possible dimensional changes of timber under the influence of changing moisture content when contact surfaces may be interrupted.

\section{Conclusions}

Design assumptions for knee joints notably affect system's deformations under the external load, as well as internal force values. Developing deformations in the semi-rigid knee connection produce up to $90 \%$ bigger vertical displacement at an apex point and 96\% bigger horizontal displacement at knee joint comparing with the rigid knee joint model.
Influence of semi-rigid behaviour of knee joint to values of internal forces is negligible. It is expected that bending moment increases of about $2 \%$ comparing with the traditional model.

Also, it is worthwhile to note that the portal frame behaviour under long-term loading may result to more unfavourable effects regarding increasing deformations.

Noticeable is the fact that semi-rigid rotational stiffness is directly dependant on the distance from a connection middle point and fasteners in external circle and moment capacity of the connection. It means that stiffness of semi-rigid connection will increase if the distance from the middle point until fasteners in external point will increase and overall moment capacity of connection will not decrease.

\section{References}

1. Bouchair, A., Racher, P., \& Bocquet, J.F. (2007). Analysis of dowelled timber to timber moment-resisting joints. Materials and Structures, Vol. 40, Issue 10, December 2007, 1127-1141. DOI: 10.1617/s11527006-9210-0.

2. European committee for standardization. (2008). Eurocode 5: Design of timber structures - Part 1-1: General Common rules and rules for buildings. Proceedings of the ICE - Civil Engineering. DOI: 10.1680/ cien.2001.144.6.39.

3. Fokkens, T.J.H. (2017). Behaviour timber moment connections with dowel-type fasteners reinforced with self- tapping screws in seismic areas. THESIS. Eindhoven University of Technology.

4. Gehloff, M., Closen, M., \& Lam, F. (2010). Reduced edge distances in bolted timber moment connections with perpendicular to grain reinforcements. In Proceedings of the 11th World Conference on Timber Engineering 2010, WCTE 2010, Vol. 2, 970-977. ISBN: 978-162276175-3.

5. Hochreiner, G., Riedl, C., Schweigler, M., Bader, T.K., \& Eberhardsteiner, J. (2016). Matrix failure of multidowel type connections - Engineering modelling and parameter study. WCTE 2016 - World Conference on Timber Engineering.

6. Leichti, R.J., Hyde, R.A., French, M.L., \& Camillos, S.G. (2000). The continuum of connection rigidity in timber structures. Wood and Fiber Science, Vol. 32, Issue 1, January 2000, 11-19. ISSN: 07356161.

7. Malo, K.A., \& Stamatopoulos, H. (2016). Connections With Threaded Rods in Moment Resisting Frames. Proceedings of the WCTE 2016 World Conference on Timber Engineering, Vienna / Austria, August 22-25, 2016, (2), 1-2.

8. Morris, H., \& Quenneville, P. (2010). Moment deformation of multi-nailed joints in LVL-development of a long term test procedure. In Proceedings of the 11th World Conference on Timber Engineering 2010, WCTE 2010, Vol. 4, 2741-2748. ISBN: 978-162276175-3.

9. Ormarsson, S., Dahlblom, O., \& Nygaard, M.J. (2010). Finite element simulation of mechanical and moisture-related stresses in laterally loaded multi-dowel timber connections. In Proceedings of the 11th World Conference on Timber Engineering 2010, WCTE 2010, Vol. 4, 3213-3220. ISBN: 978-1622761753.

10. Ozola, L., \& Fabriciuss, J. (2019). Assessment of Semi-Rigidity of Dowel Type Knee Joint between Timber Elements, IOP Conference Series: Materials Science and Engineering, Vol. 471, $4^{\text {th }}$ World Multidisciplinary Civil Engineering, Architecture, Urban Planning Symposium (WMCAUS 2018), 052073 - ISSN 1757899X

11. Porteous, J., \& Kermani, A. (2013). Structural timber design to Eurocode 5. Chichester, West Sussex, UK: John Wiley \& Sons Inc.

12. Scheibmair, F., \& Quenneville, P. (2010). Expedient moment connections for large scale portral frame structures. In Proceedings of the 11th World Conference on Timber Engineering 2010, WCTE 2010, Vol. 3, 1916-1920. ISBN: 978-162276175-3.

13. Scheibmair, F., \& Quenneville, P. (2014). Moment connection for quick assembly of timber portal frame buildings: Theory and validation. Journal of Structural Engineering (United States), Vol. 140, Issue 1, January 2014, 1127-1141. DOI: 10.1061/(ASCE)ST.1943-541X.0000728. 
14. Schweigler, M., Bader, T.K., \& Hochreiner, G. (2018). Engineering modeling of semi-rigid joints with dowel-type fasteners for nonlinear analysis of timber structures. Engineering Structures, 171, $123-139$. DOI: 10.1016/J.ENGSTRUCT.2018.05.063.

15. Timber Engineering. (1995). Step 1. Edited by H.J. Blaß, P. Aune, B.S. Choo, R. Görlacher, D.R. Griffiths, B.O. Hilson, P. Racher, G. Steck. Netherlands: Centrum Hout. 